\title{
A PREOCUPAÇÃO COM UMA ÉTICA DA ALTERIDADE NA RELAÇÃO EDUCADOR/EDUCANDO
}

Neimar de ALMEIDA ${ }^{\mathbf{1}}$

Universidade de Brasília - UNB neimardealmeida@yahoo.com.br

Resumo: O presente trabalho estrutura-se, sobretudo, a partir da comparação da Ética da Alteridade, tendo como pressuposto teórico textos do filósofo lituano-francês Emmanuel Lévinas, com a realidade educacional, no que tange à relação educador/educando. Em busca dessa aproximação entre ética da alteridade $e$ educação, propõe-se identificar a preocupação com o "outro", por parte dos educadores, no meio educacional. Assim, os objetivos foram o de apresentar a Ética da Alteridade de acordo com o autor já mencionado e verificar sua efetividade junto aos sujeitos da educação de uma escola de ensino médio do $D F^{2}$, se há uma preocupação com essa ética, por parte dos educadores desse Centro de Ensino. A metodologia utilizada foi um "estudo de caso", através de uma pesquisa oral junto aos educadores, e um debate, através de questinamentos junto aos educandos. A partir da investigação, o trabalho mostrará que há essa preocupação por parte dos educadores. Chegouse a essa conclusão a partir do diálogo com os educadores, mas, principalmente, pelo relato dos alunos envolvidos. $O$ intuito é, além de verificar a proximidade entre Ética da alteridade $e$ educação, demostrar a importância e o impacto desse pensamento no desenvolvimento humano e na aprendizagem dos educandos.

Palavras-chave: Ética da Alteridade. Educação. Emmanuel Lévinas.

\begin{abstract}
This paper is structured, above all, from the Ethics of Otherness comparison with theoretical assumption from the LithuanianFrench philosopher Emmanuel Levinas, with the educational reality, when it comes to teacher / student relationship. In pursuit of this approach between ethics of otherness and education is proposed to identify the concern with the "other" on the part of educators in the educational environment. The objectives were to present the Ethics of Otherness according to the author mentioned and check with the subject of education a high school DF, if there is concern that ethic on the part of educators of this Learning Center. The methodology used was a "case study" through an oral survey of educators and debate, through questioning, with students. From the research, the work will show that there is this concern from educators. This conclusion was based on dialogue with educators, but especially as the reporting of the students involved. The intention is in addition to verify this proximity between ethics of otherness and education, demonstrate the importance and the impact of that thought in human development and learning of students.
\end{abstract}

Keywords: Ethics of Otherness. Education. Emmanuel Levinas.

\footnotetext{
${ }^{1}$ Graduado em Filosofia pela Universidade Estadual do Oeste do Paraná (2009). Especialização em Direitos Humanos - UNB (2015). Atualmente é mestrando em Filosofia pela Universidade de Brasília - UNB. Membro do Grupo de Pesquisa "Filosofia antiga e medieval" da UnB

${ }^{2}$ Optou-se por preservar o nome da escola. Trata-se de uma escola da Rede Pública de Ensino de uma cidade satélite do Distrito Federal.
} 


\section{Introdução}

O ser humano não vem do nada. Ele não é uma ilha deserta. Toda pessoa é um ser de relação, pois, desde o nascimento, necessita do Outro para sobreviver e constituir-se subjetivamente como pessoa, tornando-se responsável por outrem.

O ambiente escolar não é feito de sujeitos fechados em si, mas de sujeitos que se relacionam em sociedade. Essas relações são marcadas pela diversidade e, por esse motivo, também marcadas pelo conflito, conflito que é fruto do individualismo.

O fato é que, muitas vezes, não há uma preocupação com a alteridade, mas com a superioridade do $E u$. A sociedade, a natureza e tudo aquilo que está fora, parece ser dominado e controlado pelo sujeito. O sujeito é dono de si e, como tal, tenta se impor como dono também do outro, estabelecendo uma relação conflitosa de poder.

É no contexto escolar que podemos intervir e buscar amenizar essa relação, objetivando encontrar soluções para o problema da falta de respeito, não acolhimento e falha de responsabilidade para com a pessoa do outro. Os responsáveis pela educação assumem um papel ético com os educandos, um papel de responsáveis pela pessoa do outro.

Diante disso, é preciso conscientizar-se da necessidade de sair de si para o Outro, acolher e se responsabilizar pelo Outro, através de um relacionamento ético de abertura ao diferente, para, assim, estar-se-a formando pessoas também preocupadas com a alteridade diante da diversidade cultural.

Na era moderna, o convívio humano é marcado pelo individualismo, a era da maioridade da razão foi também a era da superioridade do indivíduo sobre qualquer exterioridade: Deus, natureza e o outro - o próprio ser humano.

A modernidade tem-se ocupado a ampliar a capacidade do domínio do ser humano sobre a natureza, a sociedade, sobre o Outro e a negação do transcendente. Isso, evidentemente, produz uma grande reviravolta na atitude do ser humano em relação à realidade, pois, em vez de algo dado, aquilo que está aí, para mim, fora de mim, emerge como algo que o homem pode consolidar. Portanto, como algo que não pertence mais à ordem natural, mas é resultado de um processo da própria razão e ação humana. Porém, é no próprio século XX, que podemos verificar grandes tragédias desta inversão de valores, da dominação do homem sobre tudo. 
Os valores da alteridade devem ser cultivados em nosso mundo educacional. É preciso despertar nos jovens a valorização do Outro. Valorização daquilo que não pertence ao Eu, mas que contribui e determina, muitas vezes o próprio $\mathrm{Eu}$.

Diante da diversidade cultural, é necessário tornar-se mais humanizado. É no ambiente escolar que os indivíduos se deparam com a diversidade e com a oportunidade de aprender a conviver com ela. A escola é o lugar onde aprofunda-se o tornar-se humano, um humano de relações.

Por isso, torna-se necessário pensar o outro não como um problema, obstáculo para o $e u$ e nem reduzido ao $e u$, mas "um outro humano, marcado por suas especificidades, pela cultura de que faz parte, por suas crenças, ideias, valores, características físicas" (PULINO, 2014, p. 4), e que precisa ser acolhido.

Os responsáveis pela educação são os primeiros responsáveis, no ambiente escolar, para a concretização do tornar-se humano. Para que isso seja possível, é necessário conscientizá-los do papel fundamental que desempenham nesse processo. Processo de acolhimento do outro, mas, principalmente, de responsabilidade para com esse Outro, na sua formação para o acolhimento de outros em uma rede de diversidade e de relações.

Além disso, o processo de acolhimento e de responsabilidade para com outrem, por parte dos responsáveis pela educação, tem grande importância e impacto não só no desenvolvimento humano, mas também na aprendizagem dos educandos.

Diante disso, esta pesquisa se propôs a estudar o ambiente escolar e a possibilidade de encontrar nele traços desta alteridade. Parte-se da ética da alteridade, definida pelo filósofo francês Emmanuel Lévinas ${ }^{3}$.

Nesse sentido, o objetivo principal desta pesquisa é identificar, na relação educador/educando, na escola selecionada para tal, se há uma preocupação com a alteridade, acolhimento e responsabilidade para com o Outro.

A partir desse objetivo geral, são propostos os seguintes objetivos específicos: i) descrever o que é ética da alteridade, partindo principalmente do pensamento de Emmanuel Lévinas; ii) identificar, junto aos educadores e direção e principalmente entre os educandos, se há essa

\footnotetext{
${ }^{3}$ Lituano de origem, Emmanuel Lévinas (1905 - 1995) com 12 anos está na Ucrânia, onde, adolescente, é testemunha da revolução russa; no fim da década de 1920, Lévinas está em Friburgo, na Brisgóvia, para assistir às aulas de Husserl; em Friburgo, conhece também Heidegger. $\mathrm{E}$, de um e do outro, em primeiro lugar, tornará conhecido o pensamento na França, onde se estabelecera desde 1923 (Reale, Antiseri, 2006, p.423).

MARGENS - Revista Interdisciplinar

Versão Digital - ISSN: 1982-5374

Dossiê: Trabalho e Educação Básica

VOL.11. N. 16. Jun 2017. (p. 193-209)
} 
preocupação com a alteridade na relação dos educadores com os educandos e; iii) descrever, a partir do estudo realizado, como é vista a alteridade pelos sujeitos da educação na escola.

\section{Metodologia}

Este processo de intervenção terá como base metodológica o estudo de caso. Segundo Yin (2001), pode-se afirmar que um projeto de pesquisa que envolva o Método do Estudo de Caso envolve três fases distintas, a saber: (a) a escolha do referencial teórico sobre o qual se pretende trabalhar; (b) a condução do estudo de caso, com a coleta e análise de dados, culminando com o relatório do caso; e (c) a análise dos dados obtidos à luz da teoria selecionada, interpretando os resultados.

De acordo com Ludke e André (1986), um estudo de caso deve ser aplicado quando o interesse do pesquisador consiste em pesquisar uma situação singular, particular. Assim, esse estudo deve ser sempre bem delimitado, devendo ter seus contornos claramente definidos no desenvolver do estudo.

Santos (1999) salienta que o estudo de caso incide na seleção de um objeto de pesquisa restrito, com o objetivo de aprofundar-lhe os aspectos característicos. É comum, também, o estudo de caso quando se trata de reconhecer, em um caso específico, um padrão científico já delineado, no qual possa ser enquadrado.

Como esclarece Oliveira (2010), a preocupação desse tipo de pesquisa é retratar a complexidade de uma situação particular, focalizando o problema em seu aspecto total. O pesquisador usa uma variedade de fontes para coleta de dados, que são colhidos em vários momentos da pesquisa, e, em situações diversas, com diferentes tipos de sujeito. Em uma pesquisa escolar, devem-se escutar professores e alunos, e o resultado de todo esse processo investigativo é apresentado em formato de relatório final. Sua linguagem escrita aparece de maneira informal, num estilo de narração, transmitindo claramente o caso estudado.

\section{Referencial teórico}

O principal referencial para tal pesquisa, como já foi mencionado acima, é a "ética da alteridade" proposta por Emmanuel Lévinas. Para tanto, torna-se necessário definir como Lévinas esclarece o tema. 
Emmanuel Lévinas critica a tradição filosófica ocidental, que, primando pela ontologia, através de conceitos universais, buscou sempre a totalidade ${ }^{4}$. Para ele as filosofias totalizantes submetem o Outro ao Mesmo ${ }^{5}$ sem respeitar o que é particular de cada um. A saída para problema da totalidade, segundo o autor, seria uma filosofia do infinito ${ }^{6}$, que não reduzisse o Outro a um conceito a partir do $E u$, mas que, através da manifestação da sua face ${ }^{7}$, o $E u$ formasse uma consciência ética.

A ideia de infinito é um conceito que ultrapassa a própria ideia de infinito, ela não se acomoda no Mesmo, vai além de toda conceitualização possível. Sobre isso, assevera Lévinas (1997, p.209): “Ao pensar o infinito - o eu imediatamente pensa mais do que pensa. O infinito não entra na ideia do infinito, não é apreendido, essa ideia não é um conceito".

Com a ideia de infinito, o Outro, diferente e maior do que Mesmo, pode ser pensado como ele é, ou seja, totalmente Outro. A ideia de infinito, para o autor, se manifesta no rosto do Outro.

O rosto do Outro é, para Lévinas, aquilo que melhor demonstra a ideia de infinito, pois o $E u$ não consegue aprisioná-lo em forma de conceito. É “uma relação com o exterior, com o Outro, sem que essa exterioridade possa integrar-se no Mesmo" (LÉVINAS, 1997, p.209). O rosto é um totalmente Outro que se apresenta sempre como exterioridade, ele é linguagem que fala a um $E u$.

Segundo Pivatto (2001), sendo o outro completamente exterior a mim, e situando-se a sua verdade num infinito que não domino, resta-me acolhê-lo e esperar que ele me fale, convidandome à relação ética. Acolher o rosto é, então, a apreensão daquilo que o outro tem para me dizer, vindo de uma distância da qual nada sei e sobre a qual nada posso.

Para Lévinas (1997), quando acolhe-se alguém como rosto, não importa que seja rico ou pobre, desta ou daquela etnia, cultura, religião, ideologia, etc., exercendo esta ou aquela profissão, desempenhando este ou aquele cargo, com este ou aquele passado, com este ou aquele presente,

\footnotetext{
${ }^{4}$ Para Lévinas, totalidade é a redução de tudo que é externo a conceitos universais, a fim de que o sujeito possa apreendê-lo. Filosofias da totalidade são todas aquelas filosofias que primam pela autonomia.

5 Lévinas usa os termos "Outro" e "Mesmo", no sentido em que este diz do "eu" totalizante das filosofias da autonomia, enquanto aquele se refere à ideia de infinito, ao totalmente Outro, que não se reduz a um conceito universal.

${ }^{6}$ Infinito, para Lévinas, é aquilo que transcende a própria ideia de infinito, o infinito é maior que o "eu" e por isso, não pode se reduzir ao Mesmo.

7 "A face do Outro não é um objeto de um pensamento pelo qual o Outro é um dado; não é um objeto capturável por uma verdade concebida como adequação. O Outro não é um "dado" que é agarrado, como se pudéssemos estender as mãos sobre ele. O Outro se impõe com sua irredutível alteridade: o Outro me olha e se refere a mim, e se desfaz da ideia que dele tenho em mente" (REALE, ANTISERI, 2006, p. 424/425). Os termos "face" e "rosto" usados no texto, carregam o mesmo sentido.

MARGENS - Revista Interdisciplinar

Versão Digital - ISSN: 1982-5374

Dossiê: Trabalho e Educação Básica

VOL.11. N. 16. Jun 2017. (p. 193-209)
} 
uma vez que nada disso é importante, porque nada disso conta. O rosto significa por si mesmo, e isso basta.

A ideia do infinito em mim tem a função de "questionar a minha liberdade". Assim, ela não reduziria o Outro ao Mesmo e estaria salva da crítica a si mesma. "A face do Outro entra em nosso mundo, é uma 'visitação'. É responsabilidade: olha e volta a me olhar, torna-me imediatamente responsável” (REALE e ANTISERI, 2006, p. 423).

Segundo Lévinas (1997, p. 215), o aumento da exigência que tenho em relação a mim mesmo agrava o juízo que incide sobre mim, isto é, a minha responsabilidade. "E o agravamento da minha responsabilidade aumenta essas exigências. Nesse movimento, a minha liberdade não tem a última palavra".

A liberdade, nesse caso, fica submetida à ideia de infinito, ou seja, a manifestação do Outro é maior que a minha liberdade, por isso, eu não posso me apropriar dele. A consciência moral, seria então, justamente a sensibilidade para perceber o infinito e então respeitar o Outro como Outro.

Para Emmanuel Lévinas (1988, p. 92-93),

Sou eu que suporto outrem, que dele sou responsável. [...] a minha responsabilidade não cessa, ninguém pode substituir-me. De fato, trata-se de afirmar a própria identidade do eu humano a partir da responsabilidade, isto é, a partir da posição ou de-posição do eu soberano na consciência de si, deposição que é precisamente a sua responsabilidade por outrem. A responsabilidade é o que exclusivamente me incumbe e que, humanamente não posso recusar. ...Posso substituir a todos, mas ninguém pode substituir- me. [...]É precisamente neste sentido que Dostoievsky afirma: "somos todos culpados de tudo e de todos perante todos, e eu mais do que os outros".

Pode-se observar que é a responsabilidade por outrem o que constitui verdadeiramente o indivíduo, o ser único que cada um é, uma vez que, na decisão de ser para o outro, ninguém pode ser substituído. É por isso que nada é mais digno do ser humano que a responsabilidade por outrem. Aqui reside toda a ética e toda a moralidade.

Para Pivatto (2001), o outro tem significação, o outro tem sentido por si só. Tu és tu absolutamente. Compreensão alguma pode abarcá-lo, superando os poderes do eu ou da totalidade. O outro não pode ser reduzido ao mesmo, pois este é independente do mesmo. Assim, na ética levinasiana, o outro não só ganha seu espaço como tem direito, mas o relacionamento do eu com 
o outro me enriquece, visto que ouvir o outro é aprender com tudo aquilo que ignoramos e desconhecemos.

Segundo Caliman (2014, p. 221), o futuro da educação, vai realizar-se exatamente nesse terreno, isto é, na capacidade de desconstruir o medo do outro, colocando-se as bases para uma educação abalizada no acolhimento, no respeito, no diálogo, na convivência, "é necessário aprender, antes de tudo, colocar em dúvida, a questionar a legitimidade de certos preconceitos nossos (culturais, étnicos), na tentativa de encontrar um $\mathrm{Tu}$ que nos enriqueça com sua diversidade".

A educação, tendo como base essa ética, implica saída. Lévinas leva a pensar que uma nova educação que busque educar para a responsabilidade, hospitalidade, deve partir dos conceitos de proximidade e substituição, não uma educação a uma responsabilidade genérica, mas a uma responsabilidade que nos leva até a substituição ${ }^{8}$, o Mesmo no lugar do Outro. Mas o que Lévinas entende por responsabilidade? Afirma Lévinas (1988, p.87): “entendo por responsabilidade como responsabilidade por Outrem, portanto, responsabilidade por aquilo que não fui eu que fiz, ou não me diz respeito; ou que precisamente me diz respeito, é por mim abordado como rosto”.

A exigência ética é a de dar resposta, de fazer tudo para encontrar recursos, mas, ainda assim, ninguém pode fazer o impossível. Afirma Lévinas (1988, p. 89):

O laço com outrem só se aperta como responsabilidade, quer esta seja, aliás, aceita ou rejeitada, se saiba ou não como assumi-la, possamos ou não fazer qualquer coisa de concreto por outrem: Dizer: eis-me aqui. Fazer alguma coisa por outrem. Dar. Ser espírito humano é isso.

Portanto, a partir da esteira do pensamento de Lévinas, é possível pensar as bases sobre as quais se estrutura uma matriz de educação humanizadora, pautada, sobretudo, no acolhimento sensível do outro em sua sacralidade. Nesse sentido, parece que o autor está defendendo, em última análise, uma pedagogia do acolhimento passivo e responsável de outrem. Essa pedagogia da responsabilidade exige um compromisso ético, que se traduz em substituição, em que posso substituir a todos, mas ninguém pode substituir-me perante outrem.

\footnotetext{
8 "A ética significa a partir da minha responsabilidade inalienável pelo outro, responsabilidade esta que conduz o sujeito à substituição, condicão - in-condicao - na qual ele toma o lugar do outro, respondendo inclusive pelas faltas que ele comete. Pela substituição, o eu é expulso para fora do ser" (Fabri, 1997, p. 146).
} 
Esta pesquisa, como já foi asseverado, tem como base principal a ética da alteridade, a partir, principalmente, do pensamento de Lévinas. Porém, algumas pesquisas já feitas, partindo desse mesmo pressuposto teórico, ajudaram no melhor esclarecimento sobre o tema.

Segundo Costa e Diez (2012), a educação como alteridade ética implica a experiência educativa como resistência a totalitarismos e aniquilamento do outro. $\mathrm{O}$ Eu assume uma atitude de abertura e de escuta à palavra que vem do outro, pois é o outro que me permite pensar a educação como novidade, encontro, respeito à alteridade, abertura e aprendizagem. Assim, o professor é um mediador que precisa colocar-se no processo de aprendizagem como ponte e não como barreira. "Este não é outro acontecimento senão o encontro que faz cada pessoa ser mais humana e que vai se constituindo à medida que se abre ao infinito do outro" (COSTA e DIEZ, 2012, p. 9).

De acordo com Paulo Freire, quando se pensa em uma educação para a reponsabilidade é necessário que haja a "participação livre e crítica dos educandos" (FREIRE, 2011, p. 9). O professor que se preocupa com uma sociedade mais humanizada tem abertura ao diálogo contínuo com seus alunos. "Existir é um conceito dinâmico. Implica uma dialogação eterna do homem com o homem. Do homem com seu Criador.” (Ibidem, 2011, p. 12).

Para Silva (2011), compreende-se que eu (sujeito), a partir da minha subjetividade, conheço o outro e sou reconhecido pelo outro a partir da subjetividade dele. É, justamente, este exercício de alteridade que enriquece as relações humanas. E, na escola, a alteridade pode ser compreendida como um diferencial nas relações entre os professores e alunos.

\section{Coleta e análise dos dados}

\section{Apresentação da proposta à escola/direção e professores}

Foi-se bem recepcionado pela diretora da escola. Falou-se sobre a pesquisa e da possibilidade de encaixar alguns horários em que se pudesse realizar a coleta dos dados junto aos alunos e conversar com os professores. Com a autorização da direção, conversou-se com alguns professores e passou-se a realizar a pesquisa junto aos alunos.

A conversa com o corpo docente da escola não atingiu o total dos professores. Dialogou-se com alguns professores sobre o problema da pesquisa e o referencial utilizado. Quando questionados a respeito do que seria ética da alteridade, as principais respostas dos professores foram que: "sobre alteridade sim, porém, sobre 'ética da alteridade' não”. 
Depois de explicar o que seria ética da alteridade, em Lévinas, questionou-se sobre a importância deste princípio ético na relação deles, professores, com seus alunos. Os professores, de forma unânime, destacaram que é essencial essa relação. Um dos professores comentou que: “muitos alunos têm a necessidade de nosso apoio, não só nos conteúdos, mas nas dificuldades da vida. Precisamos, muitas vezes, nos colocar no lugar deles. São totalmente diferentes de nós, realidades diferentes".

Isso vai de encontro ao que propõe Lévinas. O outro é infinitamente outro e deve ser acolhido como tal. "A relação com outrem ou o discurso é uma relação não alérgica, uma relação ética, mas o discurso acolhido é um ensinamento. $\mathrm{O}$ ensinamento não se reduz, porém, à maiêutica." (LÉVINAS, 1997, p. 37).

Outros professores destacaram que, quando se pensa a alteridade para o ambiente escolar, se pensa que todo ser humano, independentemente de sua raça, cor e condições financeiras, deve ter o direito a educação, e que a relação professor e aluno deve transcender esse ambiente escolar, de forma que ambos se sintam respeitados e amados. Destacaram também que isso favorece no amadurecimento de cada ser humano que está em processo formação.

\section{Coleta dos dados junto aos estudantes e análise}

\section{Conheciam ou já tinham ouvido falar em ética da alteridade?}

Quando questionados sobre se já conheciam ou já tinham ouvido falar da ética da alteridade, os alunos destacaram que, não da forma como foi apresentada, porém essa maneira de ver os outros, essa maneira de conviver com os outros, já os era um tanto conhecida. Destacaram, além da escola, como um espaço onde se falava desse respeito para com os outros, o ambiente familiar e também a igreja que frequentam.

Assim, perceberam-se aspectos que contribuem para o pensamento da ética da alteridade no ambiente escolar, a família e as instituições sociais. Quando se fala da escola como um ambiente propício de desenvolvimento desse pensamento ético, não se pode tirar da família a tarefa formadora e educadora. Esta precisa estar atenta, acompanhando seus filhos, e colocando-lhes os limites necessários para que cresçam como pessoas saudáveis, capazes de viver em sociedade. 
É importante destacar aqui o que afirma Paulo Freire, e observar que os pais devem assumir as atividades propostas pela escola. "É indispensável que os pais tomem parte das discussões com os filhos em torno desse amanhã. Não podem nem devem omitir-se, mas precisam saber e assumir que o futuro é de seus filhos e seu." (FREIRE, 1996, p.106).

\section{É importante essa ética no ambiente escolar, na relação professor/aluno?}

Percebeu-se a unanimidade nas respostas dadas pelos alunos com relação a esse item. Alguns aspectos mais importantes que foram destacados:

Aluno A: "Quando os professores têm preocupação com nós, com cada um, individualmente, há aquilo que é mais importante na convivência humana, harmonia. Não tem como viver sem harmonia, não tem como estudar sem harmonia".

Aluno B: "Esse respeito ao outro é o que faz as pessoas serem diferentes. A ética, vista dessa forma, vai além do respeitar, é compreender como o outro é".

Essa resposta vai ao encontro do que afirma Pivatto (2001), que o outro tem significação, que o outro tem sentido por si só. $\mathrm{Na}$ ética levinasiana, o outro não só é respeitado, mas o relacionamento do eu com o outro me enriquece. Ser compreendido enriquece a personalidade de cada um, dá espaço à diversidade.

Aluno C: "É importante para a aprendizagem. Vamos conviver o ano todo, por isso precisamos ter um bom relacionamento. Nossa relação com o professor interfere na nossa aprendizagem. Aprendemos mais facilmente, quando nossa relação com o professor é próxima.

É evidente, a partir da resposta deste aluno, o que Caliman defende sobre o futuro da educação. Segundo ele, a educação vai realizar-se exatamente nesse terreno, na capacidade de desconstruir o "medo do Outro", e a partir de identificado o "medo", acolher, respeitar e dialogar, na "tentativa de encontrar um Tu" (CALIMAN, 2014, p.221). O professor, muitas vezes, é determinante na aprendizagem de seus alunos.

Algo importante que também se pode destacar a partir dessa resposta é o que Lévinas define como responsabilidade. "Responsabilidade por aquilo que não fui eu que fiz, ou não me diz respeito" (LÉVINAS, 1988, p. 87). Ou seja, o que diz respeito ao professor o fato do aluno 
apreender ou não? Segundo a ótica de Lévinas, tudo. O professor é responsável ao ponto de substituir-se, colocar-se no lugar do aluno.

Aluno D: "Diante de tantas crenças, essa ética é importante para se ter respeito à religião. Cada religião tem uma maneira de pensar e refletir sobre uma divindade. Há também aqueles que não acreditam. É preciso saber respeitar isso".

Relacionado a isso, Lévinas reitera que, quando acolhemos alguém como rosto, não importa a cultura ou religião que pratica, o rosto tem significado por si só. A crença ou não crença do outro exige do eu respeito. No caso do professor, muito mais do que o respeito, exige acolhimento e responsabilidade para defender o direito à liberdade de religiosa.

\section{Há essa preocupação com a ética da alteridade, na relação dos professores com os alunos?} Onde e quando podemos visualizar?

De forma geral, os alunos acreditam que há essa preocupação dos professores. Observaramse duas formas de relatos: um relacionado à preocupação dos professores com os alunos individualmente, e outro com relação à turma como um todo.

Aluno E: "Os professores têm se preocupado sim com nós alunos. Comigo, vejo isso acontecer muito claramente e sempre. Sempre chegam para conversar, pedem como estou. Mais especificamente nos últimos meses passei por dificuldades familiares sérias e os professores e também a direção, todos os dias me procuravam para conversar, dar apoio. Acredito que foram essenciais para que eu pudesse me recuperar e ver sentido não só nos estudos, mas sentido para a vida. Ainda estou superando e sem a escola, professores e direção, não sei o que seria”.

Aluno F: "Tenho alguns professores como amigos. Partilho os problemas tanto em relação aos conteúdos, como também problemas pessoais. Eles acabem me ajudando e orientando”.

Esse primeiro relato demonstra a importância dessa ética na relação do professor com os alunos, que vai além da sala de aula. Às vezes o professor precisa entender o contexto do aluno e isso faz toda a diferença. Preocupar-se com a alteridade, nessa relação, é se preocupar com as bases que interferem na aprendizagem, e que, muitas vezes, não estão na escola.

Quando Lévinas trata da substituição, está tratando desta realidade de sair de si para o outro. Percebe-se claramente essa preocupação em sair de si para o outro, neste relato. Colocar-se no MARGENS - Revista Interdisciplinar

Dossiê: Trabalho e Educação Básica Versão Digital - ISSN: 1982-5374

VOL.11. N. 16. Jun 2017. (p. 193-209) 
lugar do outro não com uma visão fechada, mas ver o outro como infinito, alguém que eu não posso dominar, mas acolher e entender. Responsabilizar-se por aquilo que não me diz respeito e que não fui eu que fiz, acolher a realidade do outro.

Além disso, a ética da alteridade exige, segundo Lévinas, uma resposta, ter espírito humano e fazer de tudo para ajudar e contribuir por outrem, apesar de não termos a capacidade de fazer o impossível.

Aluno G: "Notando a nossa preocupação com o futuro, e indecisão com o curso universitário, os professores procuram explicar o que cada curso estuda, o que poderia ser mais interessante para cada um. As professoras de Sociologia e História irão nos levar à UNB, na Semana Universitária, justamente para ajudar na nossa decisão. A escola demonstra preocupação com isso”.

Aluno H: "Temos, na escola, um cursinho pré-vestibular aos sábados, e sabemos que os professores não recebem nada para dar aula neste cursinho. Principalmente os professores de Matemática, além de dar aula neste cursinho aos sábados, tiram dúvidas e, pela internet, disponibilizam material e lista de exercícios para estudo. O professor de Português nos atende fora de horário e corrige textos extras com assuntos voltados ao vestibular. Vejo os professores empenhados e sem receber nada em troca e isso, para mim, é preocupar-se com a alteridade”.

Nas respostas dos alunos $\mathrm{G}$ e $\mathrm{H}$, podem-se perceber aspectos que se identificam ao referencial apresentado:

Primeiro, como afirma Lévinas (1988), a alteridade como responsabilidade é uma espécie de dom para o qual não existe reciprocidade. Vale asseverar que sou responsável por outrem sem esperar a recíproca. A recíproca é assunto dele. A dedicação e a entrega aos alunos demonstrada pelos professores, através dos relatos, é sem querem nada em troca. É simplesmente uma doação e entrega que pensa no outro. A substituição é autônoma das minhas motivações porque é pura e gratuita, ou seja, “é responsabilidade pelo Outro como aquele que não se inicia em mim, é uma sensibilidade particular que leva a uma acolhida entre os seres humanos, ou de alguma forma de compaixão" (LÉVINAS, 1988, p. 89).

Como salienta Pivatto (2001), a nossa convicção de educar para a responsabilidade deve ser uma via para enriquecer a própria identidade e não para empobrecê-la. Logo, a filosofia de Levinas visa um novo relacionamento com os Outros, que leva a nos interrogarmos sobre nossos 
costumes e escolhas de vida, que esta não pode ser separada da caridade, de atividade prática em favor do próximo.

Um segundo aspecto importante a ser analisado aqui é de que se pode ajudar os outros em suas escolhas, porém não se pode definir e determinar as escolhas destes, tirando-lhes a liberdade. Percebe-se que os professores têm se esforçados em ajudar os alunos e auxiliar no encaminhamento do que desejam estudar.

Para Lévinas, a ideia do infinito em mim tem a função de "questionar a minha liberdade", assim, ela não reduziria o Outro ao Mesmo, e, portanto, "a minha liberdade não tem a última palavra" (LÉVINAS, 1997, p. 215). Sendo submetida à ideia de infinito, a liberdade do outro é maior do que a minha e, desse modo, não posso reduzir tudo do outro em mim sem dar-lhe espaço para a tomada de decisões e escolhas.

\section{Considerações finais}

O presente estudo teve como objetivo identificar se, na relação educador/educando, na escola estudada, há uma preocupação com a ética da alteridade. A partir da pesquisa realizada junto aos professores e direção, e principalmente dos dados coletados junto aos alunos, algumas considerações podem ser feitas.

Constatou-se que a maioria dos educadores da escola referida tem grande preocupação com os problemas extracurriculares dos educandos, problemas estes que interferem na aprendizagem. A responsabilidade com “aquilo que não fui eu que fiz e não me diz respeito", como expõe Lévinas, é aspecto importante para os educadores na Escola. Os professores e a direção, segundo os alunos, estão sempre atentos às dificuldades individuais dos discentes. É sentido pelos alunos o acolhimento dessa realidade, que é infinitamente outra. Faz parte do outro (educando) e é acolhida pelo eu (educador).

Também foram diagnosticados aspectos importantes da responsabilidade dos educadores com relação ao futuro acadêmico dos alunos. Ao realizar cursinho pré-vestibular, acompanhar seus alunos em encontros que possibilitam a melhor decisão em relação aos estudos acadêmicos e capacidade de concorrência para alcançar os objetivos traçados, é perceptível a reponsabilidade assumida para com o outro, o aluno. 
Pode-se concluir, através dessa pesquisa, que há uma preocupação com a ética da alteridade na escola analisada. Isso se comprovou pelos relatos dos alunos envolvidos e pela preocupação demonstrada pelos responsáveis pela educação.

Outro diagnóstico importante observado neste trabalho foi que os alunos não tinham conhecimento do termo "ética da alteridade" da forma como fora apresentado. Porém, e esse é um aspecto importante e positivo da família e da sociedade dos indivíduos aqui investigados, já tinham conhecimento da importância do respeito e da preocupação com a alteridade. Os educadores, no entanto, como era de se supor, já conheciam o termo “alteridade”. Desconheciam, porém, o sintagma "ética da alteridade" e seu significado de acordo com o autor aqui estudado.

Assim, a prática dessa concepção ética, mesmo não sendo conhecida totalmente pelos sujeitos da educação, é praticada, e isso é o mais importante e relevante para o ambiente escolar e no que tange aos resultados da atual pesquisa.

O foco do estudo aqui proposto, como já foi mencionado, foi diagnosticar essa ética da alteridade na relação educador/educando. No entanto, foi sugerido pela diretora da escola, quando da primeira conversa sobre a realização da pesquisa, a pertinência de se trabalhar essa ética para melhorar a convivência na relação aluno/aluno do Ensino Fundamental, pois estes têm grande resistência quando se trata da valorização e respeito para com o outro.

Sendo assim, dada a pertinência e amplitude do tema, sugere-se que outros trabalhos sejam realizados a fim de divulgar a importância dessa ética nas relações humanas. Como salienta o Programa Ética e Cidadania: construindo valores na escola e na sociedade, o aprender a ser cidadão é, entre outras coisas, aprender a agir com respeito, solidariedade, responsabilidade, justiça, não violência, fazer o uso do diálogo em qualquer situação e preocupar-se com o que acontece na vida em sociedade. "Esses valores e essas atitudes precisam ser aprendidos e desenvolvidos pelos alunos e, portanto, podem e devem ser ensinados na escola." (Ministério da Educação, 2007, p.4).

Que esses valores, além de serem vivenciados pelos educadores, na relação com os educandos, possam ser difundidos e ensinados aos mesmos. 


\section{Referências}

ALVES, M. A.; GHIGGI, G. Lévinas e a educação: Da pedagogia do Mesmo à pedagogia da Alteridade. Revista Sul-Americana de Filosofia e Educação. Número 15, nov/2010-abr/2011, p. 95-111.

COSTA, M. L. Lévinas: uma introdução. Trad. J. Thomaz Filho. Petrópolis, RJ: Vozes, 2000. (Coleção ética e intersubjetividade).

COSTA, W.D. \& DIEZ, C.L. A relação Eu-Outro na educação: Abertura à Alteridade. IX ANPED SUL, Seminário de Pesquisa em Educação da Região Sul. 2012.

DEMO P. Saber pensar. 4 ed. SP: Cortez, 2005.

FABRI, M. Desencantando a ontologia: subjetividade e sentido ético em Lévinas. Porto alegre: EDIPUCRS, 1997. (Coleção filosofia; 66).

FREIRE, P. Educação como prática da liberdade. 14. ed. Rio de Janeiro: Paz e Terra, 2011.

Pedagogia da autonomia: Saberes necessários a prática educativa. $11^{\mathrm{a}} \mathrm{ed}$. Rio de Janeiro; Paz e terra, 1996.

GERALDO C. (organizador). VIOLÊNCIA e direitos humanos: espaços da educação. Brasília: Liber Livro, 2013.

GIL, A. C. Como elaborar projetos de pesquisa. 4. ed. São Paulo: Atlas, 2002.

LÉVINAS, L. Totalidade e infinito. Trad. Daniel E. Guillot. Salamanca (Espanha): Ed. Sígueme, 1997.

Da existência ao existente. Trad. Paul Albert Simon, Ligia Maria de Castro Simon. São Paulo: Editora Papirus, 1998.

. Descobrindo a Existência com Husserl e Heidegger. Trad. Fernanda Oliveira. Lisboa: Piaget, 1999.

. De Dieu qui vient à lídée. Paris: J. Vnn, 1986. De Deus que vem à ideia. Pergentino Stefano Pivatto (coordenador e revisor); Trad. Marcelo Fabri, Marcelo Luiz Pelizzoli, Evandro Antônio Kuiava. Petrópolis, RJ: Vozes, 2002.

Entre nós: ensaios sobre a alteridade. Trad. Pergentino Stefano Pivatto.(coord.). Petrópolis, RJ: Vozes. 1997. 
. Ética e infinito. Trad. João Gama. Lisboa: Ed. 70, 1988.

Humanismo do outro homem. Petrópolis, RJ: Vozes, 1993.

. Transcendência e Inteligibilidade. Trad. José Freire Colaço. Lisboa: Edições 70,

1991.

LÜDKE, M.; ANDRÉ, M. E. D. A. Pesquisa em educação: abordagens qualitativas. São Paulo: EPU, 1986.

Ministério da Educação. Programa Ética e Cidadania: construindo valores na escola e na sociedade: protagonismo juvenil / organização FAFE - Fundação de Apoio à Faculdade de Educação (USP), equipe de elaboração Ulisses F. Araújo... [et al.]. Brasília: Secretaria de Educação Básica, 2007. 4 v.

OLIVEIRA, C. L. Um Apanhado Teórico-Conceitual sobre a Pesquisa Qualitativa: Tipos, Técnicas e Características. Revista Travessia. 4. Ed. 2010.

PELIZZOLI, M. L. A relação ao Outro em Husserl e Lévinas. Porto Alegre: EDIPUCRS, 1994. . Lévinas: a reconstrução da subjetividade. Porto Alegre: EDIPUCRS, 2002.

PIVATTO, P. S. A ética de Lévinas e o sentimento do Humano-Crítica à ética Ocidental e seus pressupostos. Véritas. EDIPUCRS, v. 37, n. 147, p. 325-263, 1992. . Responsabilidade e justiça em Lévinas. Véritas, Porto Alegre, v.6, n.2, junho 2001.

PULINO, L. H. C. Z. Tornar-se humano e os Direitos Humanos. Texto seção I, Módulo IV. Educação em e para os Direitos Humanos, no contexto da Diversidade Cultural. 2014.

REALE, G.; ANTISERI, D. História da filosofia: de Nietzche à escola de Frankfurt. Trad. Ivo Storniolo. São Paulo: Paulus, 2006.

SANTOS, A. R. dos. Metodologia Científica: a construção do conhecimento. $2^{\circ}$ ed. Rio de Janeiro: DP\&A editora, 1999.

SIDEKUM, A. Ética e alteridade: a subjetividade ferida. São Leopoldo: UNISINOS, 2002.

SILVA, M.T.P. da. Um estudo das representações de Alteridade na relação professor-aluno da EJA no Ensino Fundamental. Dissertação. PUCRS. Porto Alegre, 2011. 
VITTORIO, P.; ANTONIA, F.; GERALDO C. Pedagogia da Alteridade: para viajar a Cosmópolis. Brasília: Liber Livro, 2014.

YIN, R. K. Estudo de caso: planejamento e métodos. Tradução de Daniel Grassi - $2^{\circ}$ ed. Porto Alegre: Bookman, 2001. 